\title{
Macrosurgery for fingertip amputations
}

\author{
Marcos Sanmartin Fernandez \\ From 10th Congress of the Asia-Pacific Federation of Societies of Surgery fo the Hand and the 6th Congress \\ of Asia-Pacific Federation of Societies of Hand Therapists \\ Kuala Lumpur, Malaysia. 2-4 October 2014
}

Due to the high concentration of sensitive receptors, the fingertip is widely used in plenty of activities and, therefore, frequently exposed to trauma and amputation. Simple revision amputation was used in the past for the treatment of these injuries. However, replantation, revascularization, or reconstruction allows preservation of the nail, length of the digit, and, mainly, sensibility of the pulp.

Undoubtedly, the best way to restore function to an amputated digit is to restore the amputated part by microsurgical vascular anastomosis. However, the replantation of very distal segments is technically challenging due to the size and fragility of the vessels. Furthermore, the amputated part is not always available.

Reattachment of the amputated part without vascular anastomosis is described as composite graft [1]. Other authors described different ways for improving the success rate. Brent [2] described the reattachment in amputations that occurred between the lunula and the DIP joint by performing deepithelization of the amputated part and embedding it in a subcutaneous pocket in the contralateral chest. Arata et al. [3] modified this procedure using the ipsilateral palm as the pocket site.

We consider subzone 1 Ishikawa level as suitable for reconstruction without replantation. In this case, a local flap can adequately restore function and appearance. The neurovascular homodigital advancement flap [4] is the most useful flap for coverage of the amputated part. For larger areas that cannot be covered with a homodigital advancement flap, we use innervated cross finger flaps [5].

The Moberg flap is a good option to reconstruct medium-size defects of the pulp of the thumb [6]. For covering larger areas, we use the first metacarpal island flap [7]. Raising a racket flap as proposed by Holevich [8] adds safety regarding venous congestion, once a subcutaneous tunnel is avoided, and can improve cold intolerance, since

\footnotetext{
$\overline{\text { Department of Orthopaedics and Traumatology, Hospital Povisa, Vigo, 36211, }}$
} Spain

it transfers more nerve branches to the thumb allowing for a better temperature control [9].

The nail complex tissues, as hyponychium, paronychium, and sterile matrix cannot be reconstructed with local tissue. If the amputated part is available, these parts can be used as grafts applied to the flap used to reconstruct the pulp[10].

The eponychial flap [11] can be used to increase the exposed part of the nail bed. This is achieved by removing a rectangle of dorsal skin and performing a proximal translocation of the eponychium.

\section{Published: 19 May 2015}

\section{References}

Douglas B: Successful replacement of completely avulsed portions of fingers as composite grafts. Plast Reconstr Surg Transplant Bull 1959, 23(3):213-225.

. Brent B: Replantation of amputated distal phalangeal parts of fingers without vascular anastomoses using subcutaneous pockets. Plast Reconstr Surg 1979, 63(1):1-8.

3. Arata J, Ishikawa K, Soeda H, Sawabe K, Kokoroishi R, Togo T, et al: The palmar pocket method: an adjunct to the management of zone I and II fingertip amputations. J Hand Surg 2001, 26(5):945-950.

4. Katz RD: The Anterograde Homodigital Neurovascular Island Flap. J Hand Surg 2013, 38(6):1226-1233.

5. Lee NH, Pae WS, Roh SG, Oh KJ, Bae CS, Yang KM: Innervated Cross-Finger Pulp Flap for Reconstruction of the Fingertip. Arch Plast Surg 2012, 39(6):637-642.

6. Moberg E: Aspects of sensation in reconstructive surgery of the upper extremity. J Bone Joint Surg 1964, 46:817-825.

7. Hilgenfeldt O: Operativer Daumenersatz, Enkeverslag, Stuttgart. 1950.

8. Holevich J: A new method of restoring sensibility to the thumb. J Bone Joint Surg 1963, 45B(3):496-502.

9. Couceiro J, Sanmartin M: The Holevich flap revisited: a comparison with the Foucher flap - Case series. Hand Surg 2014, 19(3):496-474.

10. Hwang E, Park BH, Song SY, Jung HS, Kim CH: Fingertip Reconstruction With Simultaneous Flaps and Nail Bed Grafts Following Amputation. J Hand Surg 2013, 38(7):1307-1314.

11. Fakin RM, Biraima A, Klein H, Giovanoli $P$, Calcagni M: Primary functional and aesthetic restoration of the fingernail in distal fingertip amputations with the eponychial flap. J Hand Surg 2014, 39(5):499-504.

doi:10.1186/1753-6561-9-S3-A58

Cite this article as: Fernandez: Macrosurgery for fingertip amputations BMC Proceedings 2015 9(Suppl 3):A58 